\title{
A psychometric evaluation of the highly sensitive person scale: the components of sensory-processing sensitivity
}

\author{
Regina V. Ershova', Ekaterina V. Yarmotz ${ }^{1}$, Tatiana M. Koryagina ${ }^{1}$, Ivan V. Semeniak ${ }^{1}$, Dmitriy A. Shlyakhta² ${ }^{2}$ Eugen Tarnow ${ }^{3}$
}

\begin{abstract}
Objective: Aron and Aron (1997) developed the Highly Sensitive Person Scale (HSPS) to measure individual differences in sensory-processing sensitivity (SPS). Their experiments showed that sensitivity is a one-dimensional construct characterized by high susceptibility to both external (e.g. light, noise) and internal (hunger, pain) stimuli (Aron 2013), later studies which were conducted using the HSPS, disagreed their concept. Further studies of the SPS construct are justified by the following: a Russian version of HSPS questionnaire has not yet been developed; the inner structure of the construct has not yet been conclusively defined (Aron and Aron, 2012), a different method of statistical data analysis may be required; the vast majority of studies, were using small homogeneous groups for sampling. Thus, the purpose of the present study was the psychometric evaluation of the Highly sensitive person scale using Russian data samples.

Method: Two approaches - active and passive - were employed to collect the field data. The active approach used verbal advertising among undergraduate university students, i.e. the 'snowball method', whereas the passive approach relied on social media advertisements in Facebook and VK.com. 860 respondents participated in the study: 350 undergraduate university student volunteers (117 males, 233 females, average age 18.2) and 510 social media users ( 380 females, 130 males, average age 22.6).

Results: The results of this study did not confirm the one-dimension model of sensitivity suggested in Aron and Aron (1997), nether was the threefactor model suggested by others. The hierarchical cluster and confirmatory analyses employed for the operationalization procedure suggest that sensory processing sensitivity (SPS) can be described in a two-factor model consisting of 'Ease of Excitation' and 'Low Sensory Threshold' subscales. The "Aesthetic Sensitivity" factor was identified during hierarchical cluster analysis, but showed very low correlation with the other factors "Ease of Excitation" and "Low Sensory Threshold". This result encourages us to look deeper into the conceptual model of HSPS developed in Aron and Aron (1997).

Conclusion: The operationalization of the Russian version of HSPS confirmed that the SPS is multidimensional construct. The precise number of subscales remains open. The term sensitivity has many meanings in modern psychology, a more rigorous definition of the sensitivity construct is required.
\end{abstract}

Keywords: sensory processing sensitivity (SPS), Highly Sensitive Person Scale (HSPS), 'Ease of Excitation', 'Low Sensory Threshold'

\section{INTRODUCTION}

Aron and Aron (1) define sensitivity (sensory processing sensitivity (SPS) as a temperamental trait (not a function of an organ), which shows, how sensory information is retrieved and processed by the brain (1). The authors claim that high sensitivity results in increased susceptibility to external stimuli and manifests itself in the following forms: (1) strong emotional reactions; (2) depth of sensory information cognitive processing; (3) sensitivity to subtle detail; (4) susceptibility to excessive stimulation. They differentiate between high sensitivity and such forms of social behavior as introversion, shyness and autism, which have similar symptoms.

A series of studies showed that sensitivity is closely linked to high stress levels, ease of exhaustion, depression, anxiety, symptoms of autism, sleep and physical disorder and vulnerability to negative impacts (see e.g. 2,3,4). Sensitivity is studied as a fear predisposition factor $(5,6)$ or the internal determinant of marginal socialization of adolescents $(7)$. It is noted that sensitive individuals manifest talent, good intuition and high levels of integrity (8) and social creativity (9).

\footnotetext{
1 Department of Psychology, State University of Humanities and Social Studies, Kolomna, Russia.

2 Social and Differential Psychology Department, Peoples' Friendship University of Russia, Moscow, Russia.

3 Avalon Business Systems, Inc., New York, USA.

Correspondence: Regina V. Ershova

Department of Psychology, State University of Humanities and Social Studies, Kolomna, Russia.

E-mail: erchovareg@mail.ru
}

Received: 26 Jun 2018, Accepted: 26 Oct 2018

(C) 2018 by the authors; licensee Modestum Ltd., UK. This article is an open access article distributed under the terms and conditions of the Creative Commons Attribution License (http://creativecommons.org/licenses/by/4.0/). 
Smolewska at al. (10) argued that individuals with high level of sensitivity show deeper emotional response to positive reinforcement and have higher openness rate in the five-factor personality model.

Despite the fact that a variety of studies has been conducted in this field, it is worth mentioning that there is no universal view of the nature of sensitivity, which can be explained by the sheer number of other qualities associated with sensitivity. Russian psychology has not yet developed a separate method for studying sensitivity, which is often measured as a part (scale) of personality or temperament, e.g. see Melnikov and Yampolsky (11); Individual and Typological Questionnaire (ITQ) by Sobchik (12); Shostrom Personal Orientation Inventory (POI) (13).

Aron and Aron (1) developed the Highly Sensitive Person Scale (HSPS) to measure sensitivity. Their experiments showed that sensitivity is a one-dimensional construct characterized by high susceptibility to both external (e.g. light, noise) and internal (hunger, pain) stimuli (14). Hofmann and Bitran (4) and Neal et al. (15) also confirmed that the sensory processing sensitivity scale (SPS) has a one-dimensional structure; however, later studies which were conducted using the HSPS, disagreed. Evans and Rothbart (16) and Cheek et al. (17) proposed a two-factor sensitivity model, Smolewska et al. (10), Liss et al. (18), Evers et al. (3), Listou Grimen and Diseth (19), and Konrad and Herzberg (20) preferred a threefactor solution. Other multifactor models were proposed by Meyer et al. (21) (four factors), and Blach and Egger (22) (six factors).

There is no uniform view of the internal structure of sensitivity, as neither two-, nor three-, nor four-, nor five-, nor six-factor models have been confirmed. The variation in the factor solutions of the sensitivity construct can be explained by: 1) inherent limits of factor analysis as a procedure which is based on excluding 'weak' factor load data, and 2) the quality of the method (scale of sensitivity). In $(10,16,19,20)$ the models that were used as baseline were not fully valid statistically; rather they fit better than the one-factor model suggested by Aron and Aron (1: three components in Smolewska et al. (10) explained $40.5 \%$ of the variance, in Listou Grimen and Diseth (19) they explained 55.2\%; four components in Meyer et al. (21) accounted for $48 \%$ dispersion. Evans and Rothbart (16) stress that their choice of a sensitivity model was based on a conceptual criterion. According to Aron and Aron (1) the popular three-component solution for the SPS structure cannot be considered final.

Further studies of the SPS construct are justified by the following: a Russian version of HSPS questionnaire has not yet been developed; since the inner structure of the construct - one- vs multi-dimensional - has not yet been conclusively defined (1), a different method of statistical data analysis may be required; the vast majority of studies, with the exception of Smolewska et al. (10); Cheek et al. (17); Konrad and Herzberg (20) were using small homogeneous groups for sampling, i.e. university students or women of approximately the same age, which can be considered as a limiting factor.

Thus, the purpose of the present study was the psychometric evaluation of the Highly sensitive person scale using Russian data samples.

\section{METHODS AND PROCEDURE}

HSPS (8) contains 27 statements each rated from 1 to 7 ( $1=$ "totally disagree") to 7 ( $7=$ "totally agree"). HSPS are used to measure both physiological reactivity to external factors (e.g. 'Are you made uncomfortable by loud noises?') and subtler sensibility ('Do you find it unpleasant to have a lot going on at one?'). The questionnaire was translated into Russian by a professional translator and then edited by a team of psychologists (subject matter experts) with a command of English, so that the translated version fully matched the Russian cultural context. After that the proofread Russian version was translated back into English. The back translation and the original English version were cross-checked by a native speaker of English (subject matter expert) to ensure that the original message of the questions was not lost in translation. The validity of the present questionnaire (Cronbach's alpha) was $\alpha=0.83$ which is comparable to the results of the other studies $(10,8)$. Test-retest reliability was carried out as a part of validation procedure. Six months after the initial test 96 student volunteers took a sensitivity retest and the correlation coefficient for the test-retest was $r=0.661$ at $\mathrm{p} \leq 0.0001$.

\section{Empirical Samples}

Two approaches - active and passive - were employed to collect the field data: verbal advertising among undergraduate university students, i.e. 'snowball method', and social media advertisements in Facebook and VK.com. Eventually 350 university student volunteers ( 233 females, 117 males, average age: $18.2( \pm 1.7)$ contacted the laboratory and filled out the HSPS questionnaire. An additional group of 510 respondents ( 380 females and 130 males, average age $22.6( \pm 7.9)$ filled out the HSPS questionnaire online. A total 860 respondents (613 females and 247 males) filled out the questionnaire. 


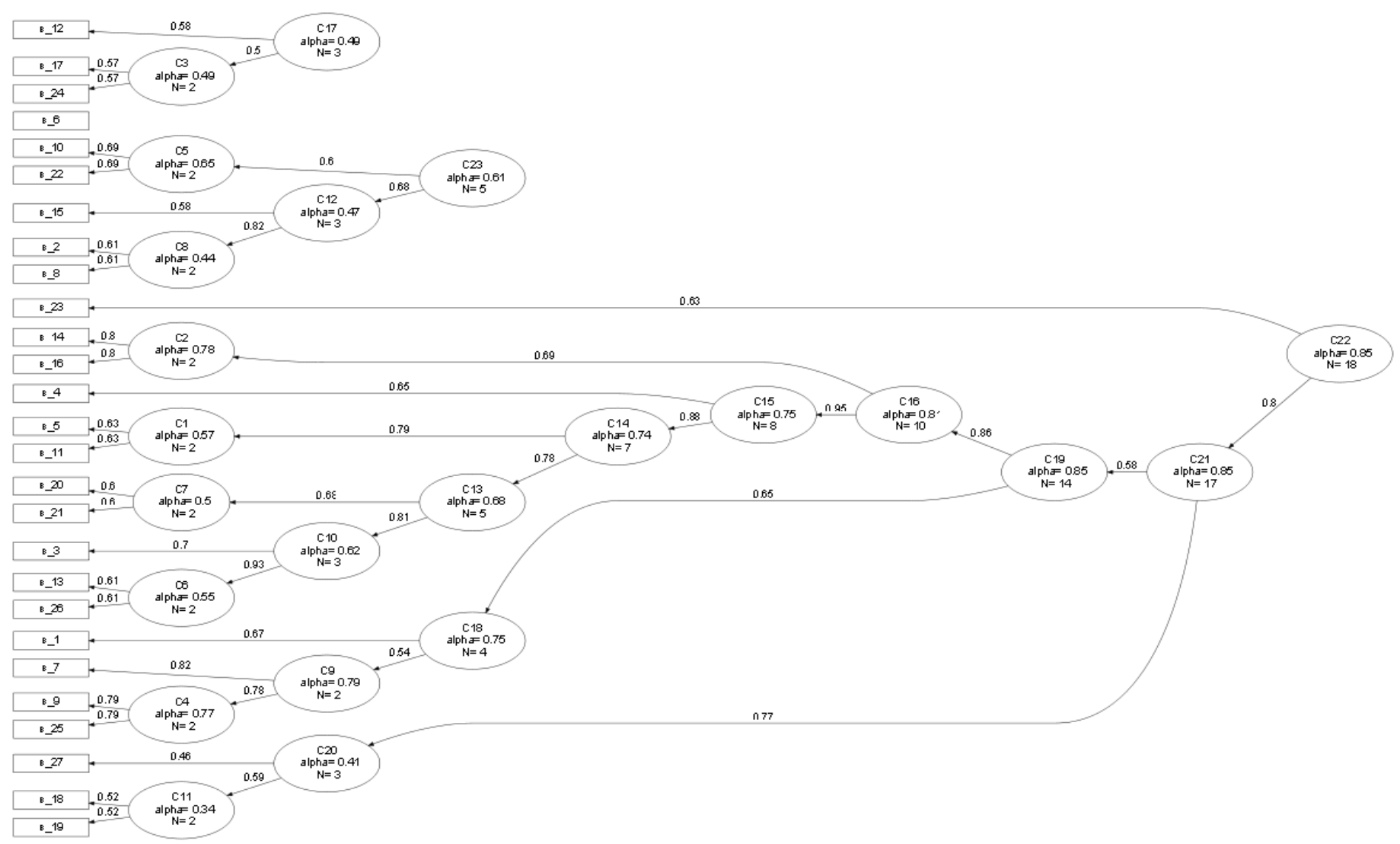

Figure 1: Dendrogram from Hierarchal Cluster Analysis (ICLAST)

Note: B_1 - number of point on the HSPS; C1 - cluster number; N - quantity of HSPS points in the cluster Source: Authors

\section{RESULTS}

The empirical samples were randomly split into two parts (430 cases in each group). An exploratory analysis (the hierarchical cluster analysis (ICLAST) (23)) on half of the sample was conducted and a confirmatory factor analysis was conducted on the second half based on the results of the exploratory analysis. The Lavaan 0.5-23.1097 software package was used for the model verification.

The 'probing' clustering (Figure 1 and Table 1$)$ allowed us to determine two sensitivity factors: C18 ( $\alpha=0.75)$ and C16 $(\alpha=0.81)$, which contribute to a higher C19 $(\alpha=0.85)$. Points on the HSPS which fell in the selected clusters are very similar to the factors in Smolewska at al. (10), Evans and Rothbart (16), and Listou Grimen and Diseth (19). The C18 cluster corresponds to the 'Low Sensory Threshold' subscale, it consists of 4 items. C16 cluster corresponds to the - 'Ease of Excitation' subscale, it consists of 10 items. The C23 cluster (5 items), clearly visible in the hierarchal analysis $(\alpha=0.61)$, is identical to that of the third sensitivity subscale - 'Aesthetic sensitivity'. However, the C23 cluster reliability coefficient is low and it does not depend on other clusters of the questionnaire, which suggests that the content of the items in it is irrelevant to the content of sensitivity scale (Figure 1).

Based on these results (Table 1 and Figure 1), the following items were eliminated from the further analysis: No. 6 "Are you particularly sensitive to the effects of caffeine?", No 12 "Are you conscientious?", No.17 "Do you try hard to avoid making mistakes or forgetting things?" No. 18 "Do you make a point to avoid violent movies and TV shows?", No. 19 "Do you become unpleasantly aroused when a lot is going on around you?", No.23 "Do you find it unpleasant to have a lot going on at once?", No.24 "Do you make it a high priority to arrange your life to avoid upsetting or overwhelming situations?" and No.27 "When you were a child, did your parents or teachers seem to see you as sensitive or shy?". These items had low reliability, internal coherence of the subscales ( $\alpha$ coefficient ranging from 0,34 to 0,49 ) and the independence of these subscales on the general sensitivity cluster. 
Table 1: Distribution of HSPS Items by Subscales in Different Studies

Source: Authors

\section{No. Sensitivity Scale Wording}

Smolewska Grimen \& $\quad$ Evans \& Present

1 Do you tire quickly from sensory stimuli

et al. (2006) Diseth (2016) Rothbart (2008) Study

2 You are aware of the subtleties in your environment more than others

excl

3 Are you more than others affected by moods of other people

4 Are you more others are sensitive to pain

You find yourself needing to withdraw during busy days, into bed or into a

5 darkened room or any place where you can have some privacy and relief from

AES

EOE

$\mathrm{EOE}$

excl.

AES

excl.

NA

NA

LST

excessive stimulation

6 Are you particularly sensitive to the effects of caffeine?

7 Are you easily overwhelmed by things like bright lights, strong smells, coarse

fabrics, or sirens close by?

8 Do you have a rich, complex inner life?

9 Are you made uncomfortable by loud noises?

AES

excl.

RS

NA

AES

10 Are you deeply moved by the arts or music?

\begin{tabular}{|c|c|c|c|}
\hline LST & excl. & excl. & excl. \\
\hline
\end{tabular}

11 Your nervous system is sometimes so exhausted that you want to hide even from

11 yourself

12 Are you conscientious?

13 Do you startle easily?

14 Do you get rattled when you have a lot to do in a short amount of time?

When people are uncomfortable in a physical environment do you tend to know

15 what needs to be done to make it more comfortable (like changing the lighting or the seating)?

\begin{tabular}{|c|c|c|c|c|c|}
\hline 16 & Are you annoyed when people try to get you to do too many things at once? & EOE & EOE & NA & EOE \\
\hline 17 & Do you try hard to avoid making mistakes or forgetting things? & EOE & excl. & NA & excl. \\
\hline 18 & Do you make a point to avoid violent movies and TV shows? & LST & excl. & NA & excl. \\
\hline 19 & Do you become unpleasantly aroused when a lot is going on around you? & LST & excl. & NA & excl. \\
\hline 20 & $\begin{array}{l}\text { Does being very hungry create a strong reaction in you, disrupting your } \\
\text { concentration or mood? }\end{array}$ & EOE & excl. & NA & $\mathrm{EOE}$ \\
\hline 21 & Do changes in your life shake you up? & EOE & EOE & NA & $\mathrm{EOE}$ \\
\hline 22 & Do you notice and enjoy delicate or fine scents, tastes, sounds, works of art? & AES & AES & RS & AES \\
\hline 23 & Do you find it unpleasant to have a lot going on at once? & EOE & EOE & NA & excl. \\
\hline 24 & $\begin{array}{l}\text { Do you make it a high priority to arrange your life to avoid upsetting or } \\
\text { overwhelming situations? }\end{array}$ & EOE & EOE & NA & excl. \\
\hline 25 & Are you bothered by intense stimuli, like loud noises or chaotic scenes? & LST & LST & NA & LST \\
\hline 26 & $\begin{array}{l}\text { When you must compete or be observed while performing a task, do you become } \\
\text { so nervous or shaky that you do much worse than you would otherwise? }\end{array}$ & EOE & EOE & NA & EOE \\
\hline 27 & $\begin{array}{l}\text { When you were a child, did your parents or teachers seem to see you as sensitive } \\
\text { or shy? }\end{array}$ & EOE & excl. & RS & excl. \\
\hline
\end{tabular}

Note: $\mathrm{EOE}=$ Ease of Excitation, AES = Aesthetic Sensitivity, STF = Sensitivity to Failure, LST = Low Sensory Threshold, NA = Negative Affectivity, RS = Relative Sensitivity, Excl= excluded from scale.

Table 2: Fit indices for the two factors and three factors models

Source: Authors

\begin{tabular}{ccccccc}
\hline Model & $\boldsymbol{X}^{\mathbf{2}}$ & $\mathbf{d f}, \boldsymbol{p}$ & $\mathbf{N N F I}(\mathrm{TLI})$ & $\mathbf{C F I}$ & $\mathbf{R M S E A}$ & $\mathbf{9 0 \% C I}$ \\
\hline 2K & 86.93 & $61,0.018$ & 0.974 & 0.980 & 0.031 & $0.014-0.046$ \\
\hline $3 \mathrm{~K}$ & 293.83 & $132,0.000$ & 0.875 & 0.882 & 0.053 & $0.046-0.062$ \\
\hline
\end{tabular}

Note: $\boldsymbol{X}^{2}$. = chi-square statistics value, $\mathrm{df}=$ number of degrees of freedom, $p=$ significance level, NNFI (TLI) = Non-normed Fit Index (Tucker-Lewis Index), $\mathrm{CFI}=$ Bentler Comparative Fit Index, RMSEA = Root Mean Square Error of Approximation, $90 \% \mathrm{Cl}=$ Confidence limits for RMSEA

Confirmatory factor analysis of the cross-validation sample $(\mathrm{N}=430)$ was conducted to verify the factorial model with correlating factors. Double loads were not included in the assessed models. Since the nonparametric methods are more adequate to a Likert scale of 7 , the models were evaluated using the WLSMV estimator (weighted least squares method), chi-square using Satorra-Bentler formula and robust evaluation of standard error. Model-data correlation values are given in Table 2.

The two-factor 2K model ('Low Sensory Threshold' and 'Ease of Excitation' factors) fits all parameters, apart from the importance of the criterion $\mathbf{X}^{2}$ and meets the coherence criteria. If the third factor - "Aesthetic Sensitivity" - is added to the model, then the coherence values drop significantly. The correlations of the factor F3 ("Aesthetic Sensitivity") with the first F1 ('Low Sensory Threshold') and the second F2 ('Ease of Excitation') are below 0.3, whereas the F2 and F3 


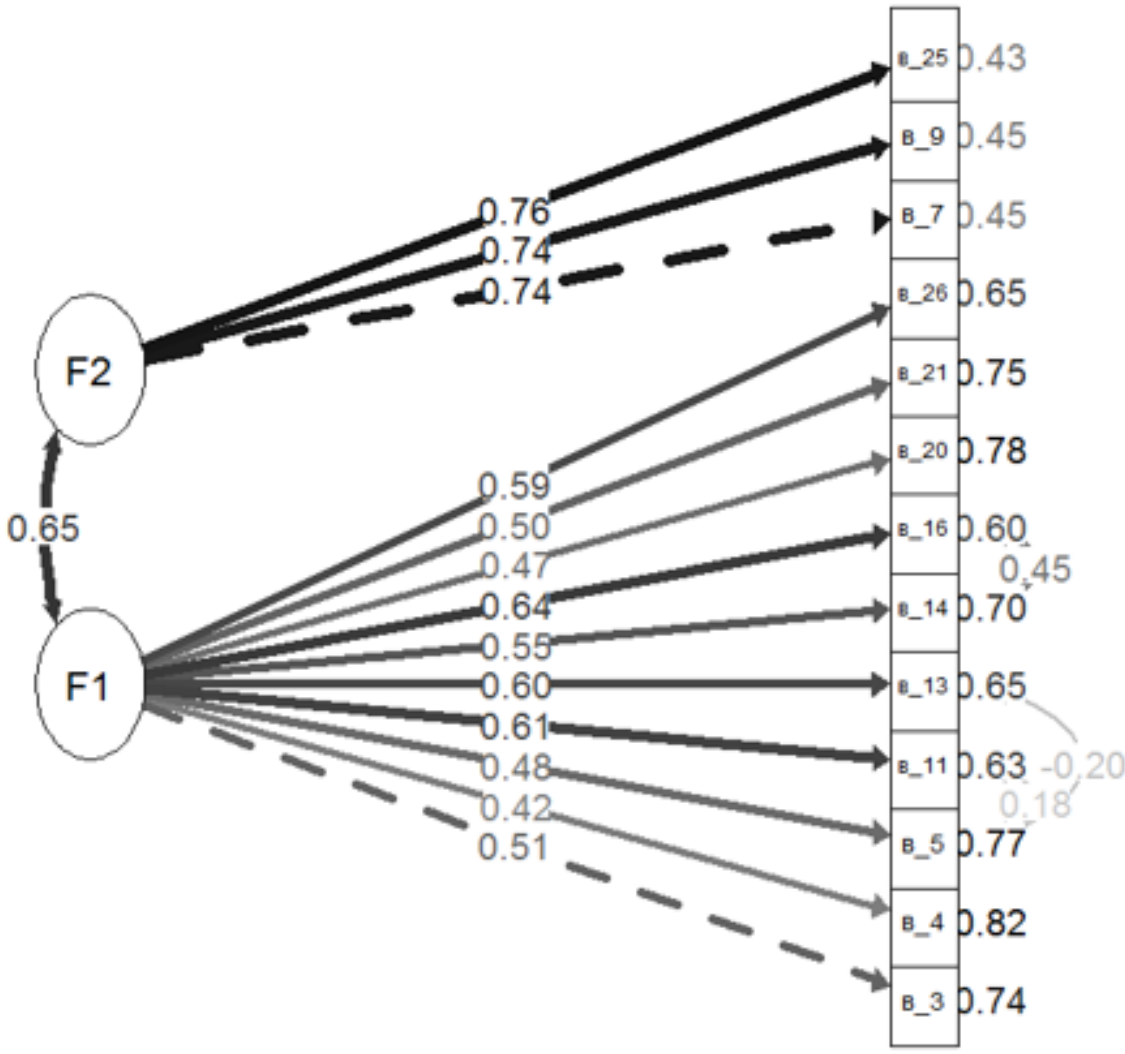

Figure 2: Standardized parameters of two factors HSPS model (all parameters are significant $p<0.001$ )

Source: Authors

Note: F1 = "Ease of Excitation" factor, F2 = "Low Sensory Threshold" factor

Table 3: Standardized loads of HSPS items to primary factors

Source: Authors

\begin{tabular}{|c|c|c|c|}
\hline No. & Factor name / Wording & Load & $\mathbf{R}_{\mathbf{2}}$ \\
\hline \multicolumn{4}{|c|}{ Ease of Excitation } \\
\hline B_3 & Are you more than others affected by moods of other people & 0.507 & 0.257 \\
\hline B_4 & Are you more others are sensitive to pain & 0.419 & 0.176 \\
\hline B_5 & $\begin{array}{l}\text { You find yourself needing to withdraw during busy days, into bed or into a darkened room or any place where you can have } \\
\text { some privacy and relief from excessive stimulation }\end{array}$ & 0.480 & 0.230 \\
\hline B_11 & Your nervous system is sometimes so exhausted that you want to hide even from yourself & 0.610 & 0.372 \\
\hline B_13 & Do you startle easily? & 0.595 & 0.354 \\
\hline B_14 & Do you get rattled when you have a lot to do in a short amount of time? & 0.548 & 0.300 \\
\hline B_16 & Are you annoyed when people try to get you to do too many things at once? & 0.635 & 0.403 \\
\hline B_20 & Does being very hungry create a strong reaction in you, disrupting your concentration or mood? & 0.468 & 0.219 \\
\hline B_21 & Do changes in your life shake you up? & 0.501 & 0.251 \\
\hline B_26 & $\begin{array}{l}\text { When you must compete or be observed while performing a task, do you become so nervous or shaky that you do much } \\
\text { worse than you would otherwise? }\end{array}$ & 0.588 & 0.345 \\
\hline \multicolumn{4}{|c|}{ Low Sensory Threshold } \\
\hline B_7 & Are you easily overwhelmed by things like bright lights, strong smells, coarse fabrics, or sirens close by? & 0.743 & 0.553 \\
\hline B_9 & Are you made uncomfortable by loud noises? & 0.742 & 0.550 \\
\hline B_25 & Are you bothered by intense stimuli, like loud noises or chaotic scenes? & 0.756 & 0.571 \\
\hline
\end{tabular}

correlation is insignificant. Loads of the B_15 and в_2 variables on the third factor by the level are lower than 0.2 (insignificant). Thus, the two-factor sensitivity model is preferable (Figure $\mathbf{2}$ and Table $\mathbf{3}$ ).

The present study was aimed to define the inner structure of the Russian version of HSPS. Analysis of the scale structure showed that some of its items lack strong correlation with the general factor and specific scales of the questionnaire, which was also shown in Smolewska et al. (10), Booth et al. (24), Listou Grimen and Diseth (19). The 8 items of the questionnaire that we have excluded (i.e. Nos 6, 12, 17, 18, 19, 23, 24 and 27) proved to be 'weak' in the studies of other researches: No.6 ("Are you particularly sensitive to the effects of caffeine?") was excluded by virtually all researchers, e.g. Booth et al. (24), Listou Grimen and Diseth (19), Evans and Rothbart (16). Items Nos 12, 17 and 18 were 
considered weak by Listou Grimen \& Diseth (19), No 19 ("Do you become unpleasantly aroused when a lot is going on around you?") was considered weak by Booth et al. (24).

The results of this study did not confirm the one-dimension model of sensitivity suggested in Aron and Aron (1), nether was the three-factor model suggested by others. The operationalization procedure for the Russian version of the HSPS suggests a bi-factor model of sensitivity with 13 questions (there were 21 questions in Booth et al. (24), 13 questions in Listou Grimen and Diseth (19), 24 questions in Smolewska et al. (10). The two components are the subscales "Ease of Excitation" and "Low Sensory Threshold". The contents of these two HSPS subscales is almost identical to the content of these subscales in Smolewska et al. (10).

The "Aesthetic Sensitivity" factor, which reflects the depth of cognitive processing of information and sensitivity to subtle detail, i.e. questions No. 2, 8, 10, 15 and 22, was identified during hierarchical cluster analysis, but showed very low correlation with the other factors "Ease of Excitation" and "Low Sensory Threshold". This means that its content is irrelevant to the overall content of the HSPS questionnaire and encourages us to look deeper into the question of whether the conceptual model developed in Aron and Aron (1) is supported by the Russian HSPS scale. Evans and Rothbart (16), discovered that the negative emotional response of varied intensity to sensory stimuli (the "Negative Affectivity" scale of HSPS), have the most weight in the HSPS structure. The results of our study confirm the conclusions of Evans and Rothbart (16), and allow us to define sensitivity as increased susceptibility to external and internal stimuli, which is expressed through negative emotional reactions and deep susceptibility (distress) to excessive stimulation. The argument of Aron and Aron (1) that the sign of the high sensitivity is the depth of cognitive information processing and sensitivity to subtle detail was not confirmed.

\section{CONCLUSIONS}

The operationalization of the Russian version of HSPS confirmed that the SPS construct is multidimensional. The precise number of subscales remains open. Since the term sensitivity has many meanings in modern psychology, a more rigorous definition of the sensitivity construct is required.

One of the limitation of the present study is the lack of randomized samples. However, a number of techniques for active and passive empirical sampling (25) were employed in order to reduce the corresponding errors. The online sample was more heterogeneous as compared to the offline sample.

Another limitation of HSPS is that it is a "self-evaluation" method, which, affects the objectivity of the collected data; sensitivity can be mixed up with other psychological symptoms and the emergence of a "social desirability effect" as sensitivity has a negative connotation for Russian males.

\section{REFERENCES}

1. Aron EN, Aron A. Sensory-processing sensitivity and its relation to introversion and emotionality. Journal of Personality and Social Psychology.1997;73:345-368. https://doi.org/10.1037/0022-3514.73.2.345

2. Benham G. The highly sensitive person: stress and physical symptom reports. Personality and Individual Differences. 2006;40:1433-1440. https://doi.org/10.1016/j.paid.2005.11.021

3. Evers A, Rasche J, Schabracq MJ. High sensory-processing sensitivity at work. International Journal of Stress Management. 2009;15:189-198. https://doi.org/10.1037/1072-5245.15.2.189

4. Hofmann SG, Bitran S. Sensory-processing sensitivity in social anxiety disorder: relationship to harm avoidance and diagnostic subtypes. Journal of Anxiety Disorders. 2007;21:944-954. https://doi.org/10.1016/j.janxdis.2006.12.003 PMid:17241764 PMCid:PMC2174907

5. Chernavsky AF. Psychophysiological preconditions for the manifestation of fear. News of the Herzen's Russian State Pedagogical University. 2007;19(45):11-19.

6. Smirnova EO, Koshkarova TA. Analysis of maternal difficulties in relations with the child (based on the material of primary school age). Psychological science and education. 2005;3:5-15.

7. Nikishina VB, Glushkova VP. Internal determinants of the process of adolescents with ADHD socialization. Izvestiya of Volgograd State Pedagogical University. 2009;9:124-126.

8. Aron E, Aron A, Jagiellowicz J. Sensory processing sensitivity: A review in the light of the evolution of biological responsivity. Personality and Social Psychology Review. 2012;16:262-282. https://doi.org/10.1177/1088868311434213 PMid:22291044 
9. Banyukhova AE, Shemelina OS. Personality aspects of creativity. Yaroslavl Pedagogical Bulletin. 2010;2(4):205211.

10. Smolewska KA, McCabe SB, Woody EZ. A psychometric evaluation of the Highly Sensitive Person Scale: The components of sensory-processing sensitivity and their relation to the BIS/BAS and "Big Five". Personality and Individual Differences. 2006;40:1269-1279. https://doi.org/10.1016/j.paid.2005.09.022

11. Melnikov V, Yampolsky L. The introduction to the experimental psychology of a person. Moscow: Prosveschenie; 1985.

12. Sobchik L. Differential methods of psychological diagnosis of neurotic disorders. Individual-typological questionnaire (ITQ). Moscow: GNC SSP Publ. 1999.

13. Alyoshina J, Gozman L, Zagika M, Kroz M. Self-actualization Inventory. Moscow: MSU Publ; 1994.

14. Aron EN. The highly sensitive person. New York: Kensington Publishing Corp; 2013.

15. Neal JA, Edelmann RJ, Glachan M. Behavioral inhibition and symptoms of anxiety and depression: is there a specific relationship with social phobia? British Journal of Clinical Psychology. 2002;41:361-374.

16. Evans $D E$, Rothbart MK. Temperamental sensitivity: Two constructs or one? Personality and Individual Differences. 2008;44:108-118.

17. Cheek JM, Bourgeois ML, Theran SA, Grimes JO, Norem JK. Interpreting the factors of the Highly Sensitive Person scale. Tampa: Poster session presented at the annual meeting of the Society for Personality and Social Psychology; 2009.

18. Liss M, Mailloux J, Erchull MJ. The relationship between sensory processing sensitivity, alexithymia, autism, depression, and anxiety. Personality and Individual Differences. 2008;45:255-259. https://doi.org/10.1016/j.paid.2008.04.009

19. Listou Grimen H, Diseth Å. Sensory Processing Sensitivity: Factors of the Highly Sensitive Person Scale and Their relationships to Personality and Subjective Health Complaints. Perceptual and motor skills. 2016;123(3):637-653. https://doi.org/10.1177/0031512516666114 PMid:27562694

20. Konrad S, Herzberg PY. Psychometric Properties and Validation of a German High Sensitive Person Scale (HSPSG). European Journal of Psychological Assessment. 2017;3:124-135. https://doi.org/10.1027/1015-5759/a000411

21. Meyer B, Ajchenbrenner M, Bowles DP. Sensory sensitivity, attachment experiences, and rejection responses among adults with borderline and avoidant features. Journal of Personality Disorders. 2005;19:641-658. https://doi.org/10.1521/pedi.2005.19.6.641 PMid:16553560

22. Blach C, Egger JW. Highly sensitive persons - an empirical investigation to a complex phenomenon. Psychological Medicine. 2014;25:4-16.

23. Revelle W. Hierarchical cluster analysis and the internal structure of tests. Multivariate Behavioral Research. 1979;14(1):57-74. https://doi.org/10.1207/s15327906mbr1401_4 PMid:26766619

24. Booth C, Standage H, Fox E. Sensory-processing sensitivity moderates the association between childhood experiences and adult life satisfaction. Personality and individual differences. 2015;87:24-29. https://doi.org/10.1016/j.paid.2015.07.020 PMid:26688599 PMCid:PMC4681093

25. Thielsch MT. Aesthetics of websites. Perception of aesthetics and their relation to content, usability and personality traits. Münster: MV Wissenschaft. 2008. Retrieved from http://www.idsymposium.de/index2691.pdf?elD=tx_naws-ecuredl $\& u=0 \& g=0 \& \mathrm{t}=1439047247 \& \mathrm{hash}=$ 163fe3efc5ccee2724cba9f95a3e3cdb6bb5985d\&file=fileadmin/secdl/2008/03_thielsch_presentation.pdf

$\diamond \diamond \diamond \diamond \diamond \diamond \diamond$

http://www.ejgm.co.uk 